\title{
Establishment of Z score reference of growth parameters for Egyptian school children and adolescents aged from 5 to 19 years: a cross sectional study
}

\author{
Ali M El-Shafie \\ Menoufia University Faculty of Medicine \\ Fady M. El-Gendy \\ Monufia University pediatric department \\ Dalia M. Allahony \\ Monufia University pediatric department \\ Zein A Omar \\ Menoufia University Faculty of Medicine \\ Mohamed A. Samir \\ Menoufia University Faculty of Medicine \\ ahmed N elbazzar ( $\sim$ Ahmed.n.elbazzar@gmail.com ) \\ Menoufia University Faculty of Medicine https://orcid.org/0000-0002-7857-7876 \\ Mohamed A. Abd El-Fattah \\ Menoufia University Faculty of Medicine
}

Amir A. Abdel Monsef

Menoufia University Faculty of Medicine

Amir M. Kairallah

Menoufia University Faculty of Medicine

Hythem M. Raafet

Menoufia University Faculty of Medicine

Ghada M.Baza

Menoufia University Faculty of Medicine

Amany G. Salah

Menoufia University Faculty of Medicine

Walaa S. Galab

Menoufia University Faculty of Medicine

\section{Zeinab A Kasemy}

Menoufia University Faculty of Medicine

wael A Bahbah

Menoufia University Faculty of Medicine 


\section{Research Article}

Keywords: Adolescent, Egyptian Z score, Growth parameters, Nutritional status, School children

Posted Date: July 7th, 2020

DOI: https://doi.org/10.21203/rs.3.rs-21588/v2

License: (c) (1) This work is licensed under a Creative Commons Attribution 4.0 International License. Read Full License

Version of Record: A version of this preprint was published on July 21st, 2020. See the published version at https://doi.org/10.3389/fped.2020.00368. 


\section{Abstract}

\section{Background:}

Growth charts are an important method for evaluating a child's health, growth and nutritional status.

\section{Objective:}

To establish Lambda - Mu- Sigma (LMS) and Z score references for assessment of growth and nutritional status in Egyptian school children and adolescents.

\section{Methods:}

A total of 34,822 Egyptian school children and adolescents from 5 to 19 years were enrolled in a cross sectional randomized study from December 2017 to November 2019 to create LMS and Z score references for weight, height and body mass index (BMI) corresponding to ages. They were selected from different districts in Egypt. Apparent Healthy children with good nutritional history and not suffering from any chronic diseases were included in the study.

\section{Results:}

Egyptian children of both sexes ( $54.3 \%$ boys and $45.7 \%$ girls) from 5 to 19 years old were studied. Then LMS and Z scores for weight for age, height for age, BMI for age of both sexes were represented in detailed tables and graphs. There was no statistically significant difference between the Egyptian Z score charts and the reference values of $\mathrm{WHO}$ for weight, height and $\mathrm{BMI}$ corresponding to age $(\mathrm{P}>0.05)$.

\section{Conclusion:}

This is the first national reference for growth and nutritional assessment using LMS and Z score charts in Egyptian school children and adolescents, this tool is essential for healthcare and research.

Key words: Adolescent - Egyptian Z score -Growth parameters- Nutritional status-School children

\section{Introduction}

Impairment in growth is one of universal public health problems, ${ }^{1}$ and its early detection and accurate diagnosis is important for early intervention. ${ }^{2}$ Age- and sex-specific growth charts are the important tools used for monitoring children's longitudinal growth. ${ }^{3-5}$

For investigating a child's growth rate, weight and height are the most common anthropometric measurements used. So assessment of weight and height plays an important role in follow up of the growth and nutritional status and early detection of its abnormalities for early intervention before permanent changes occur. ${ }^{6}$ 
Over the past decades, one of the most important health problem worldwide is the increasing pattern of childhood obesity. ${ }^{7-11}$ Beyond the research setting, Body mass index is used alone as indicator of overweight and obesity in children and adolescents. ${ }^{12} 13$

In Egypt two thirds of child mortality owed to malnutrition and stands as one of the 36 countries where $90 \%$ of the global burden of malnutrition falls. ${ }^{14}$ Pediatric overweight and obesity are considered the most prevalent nutritional disorder among both children and adolescents with $21 \%-24 \%$ of them are overweight. ${ }^{15}$

The first national charts on the physical Growth and development of children were established in $1972 .{ }^{16}$ ${ }^{17}$ This study was conducted on 2121 Egyptian children from Cairo area aged from 6- 18 years and measured weight, stature and weight/stature index using percentiles method.

\section{The second national charts were done in 2002 using the same study design and in the same district but it included more age group (from birth to 18 years). ${ }^{18}$}

In Egypt, there are two international references charts used to assess growth and nutritional status of children and adolescents aged 5-19 years, the first one is the recently updated World Health Organization (WHO) $2007^{19}$ while the second is the reference values from the Centers for Disease Control and Prevention (CDC). ${ }^{20}$ Egypt does not have its own growth reference data based on Lambda-Mu- Sigma (LMS) and Z score parameters that is constructed with a representative national sample of children and adolescents, so the aim of this study was to establish a national reference charts for assessment of growth and nutritional status in Egyptian school children and adolescents by using LMS and Z score parameters.

\section{Methods And Design}

\section{Participants}

Egypt consists of 27 governorates. Cairo is the largest governorates in terms of population, accounting for one-third of Egypt's population according to the latest statistics. Therefore this was taken into account and the largest number of participants from Cairo. To conduct the study, a cross-sectional design with a multistage random sampling technique was used. Out of 27 governorates, 3 governorates from Upper Egypt and 5 governorates including Cairo from Lower Egypt were chosen in this study. We chose 18 districts from previously chosen governorates randomly. Then facilities including basic education schools and secondary training schools were counted, and 140 facilities in the selected 8 governorates were randomly chosen. The study sample was determined based on Egypt demographic health survey 2015. ${ }^{21}$ All the socioeconomic strata were represented with weighted rural-urban representation. All details of the selected households in cities and villages in every single governorate were provided. Any 
child aged from 5-19 years old was eligible to share in the study. The process was totally computerized. The involved team (primary care physicians, paediatricians and nurses) had been subjected to a training workshop on anthropometric measurements over 2 days followed by testing to avoid inter and intra-observer bias.

Out of the week, the study was conducted in three crowded days to gather more information. They were selected from Primary health centers, Primary school and secondary school as representative of children in Egypt. Between the educational courses and during break time, children were screened in the school that was selected randomly from the list of schools.

A total of 34,822 Egyptian children from 5 to 19 years were studied from December 2017 to November 2019. Firstly, we took 35,042 who were eligible for the study, then 34,822 children and adolescents were selected as a final total sample after exclusion of 220 children on applying the inclusion and exclusion criteria.

\section{Ethics approval:}

Institutional Review Boards (IRB) of the Menoufia faculty of medicine had approved the study. Ethical approval ID is 171112Ped. Research work had been performed in accordance with the Declaration of Helsinki. Purpose of the study was explained to all mothers/guardians of the children and adolescents and informed about objective of the study with absence of any risk to their children in participation in this study and those who agreed to participate signed an informed consent to confirm their willingness to participate.

\section{Inclusion and exclusion criteria}

All apparent healthy children with good developmental and nutritional history were included in this study. We excluded any child suffering from any chronic disease (cardiac, hematological, renal, endocrinal and hepatic diseases), fever or documented underlying disease at the time of examination.

\section{Measurements and data collection}

We measured weight for age, height for age and calculate BMI for age for both sexes. All measured were collected by trained medical staff. All children were examined by identical measuring equipment. Weight was measured by a digital balanced scale (Beurer model GS 11, Germany) and height assessed by Harpenden fixed stadiometer. Device was calibrated daily. $\mathrm{BMI}$ was calculated using the formula: $\mathrm{BMI}=$ weight $(\mathrm{Kg}) /(\text { height }(\mathrm{m}))^{2}$.

\section{Patient and public involvement}


A sample of 99 children and caregivers beside 81 healthcare providers were interviewed and invited to provide us with their background questions related to anthropometric measurements. Four top questions out of 120 related ones were highlighted and studied in the attached figures. The aim of this step was to enlighten the way to our research to be relevant to the health needs.

\section{Statistical analysis:}

The LMS parameters were used to determine the standard deviation $(-3$ to +3$)$ of weight, height and BMI for both sexes. The median (M), the generalized coefficient of variation (S), and the power in the Box-Cox transformation $(\mathrm{L})$ are the content of LMS parameters. To convert the distribution of data to normal distribution, we used method of The Box-Cox transformation. The method models the data taking into consideration the degree of skewness $(L)$, central tendency $(M)$, and dispersion $(S)$. The $L, M$, and $S$ parameters are calculated and smoothed according to the method of maximum penalized likelihood. ${ }^{22} 23$ $Z$ score and LMS parameters were calculated by using the Statistical package SPSS, version 20 , for windows (SPSS Inc., Chicago, Illinois, USA) and Excel according to the following formula:

\section{$P=M[1+L S Z] 1 / L, L \neq 0$}

\section{We calculated the $z$-score values of $-3,-2,-1,0,+1,+2$, and +3 for weight, height and BMI for age. The goodness of fit of all $L, M$, and $S$ models was assessed using Q-test. ${ }^{24}$}

Student t-test for one sample was used to compare the means values of each group variable with the Egyptian and WHO reference values. For all analyses, the significance level was set at $5 \%$.

\section{Result}

\section{A total of 34,822 Egyptian children ( $54.3 \%$ boys and $45.7 \%$ girls), from 5 to 19 years of age (table 1 )}

Figure (1) shows Egyptian Z score weight for age from 5 to 19 years for boys. Figure (2) shows Egyptian $Z$ score weight for age from 5 to 19 years for girls. Figure (3) shows Egyptian $Z$ score height for age from 5 to 19 years for boys. Figure (4) shows Egyptian Z score height for age from 5 to 19 years for girls. Figure (5) shows the Egyptian Z score BMI for age from 5 year to 19 years for boys. Figure (6) shows the Egyptian Z score BMI for age from 5 year to 19 years for girl. Figure (7) shows the comparison between Egyptian Z score and WHO Z score references value (weight for age in boys). Figure (8) shows the comparison between Egyptian Z score and WHO Z score references value (weight for age in girls). Figure (9): shows the comparison between Egyptian Z score and WHO Z score references value (Height for age 
in boys). Figure (10): shows the comparison between Egyptian Z score and WHO Z score references value (Height for age in girls)

\section{Discussion}

To assess the growth and nutritional status of a child, percentiles, percent of median, and Z-scores (standard deviation scores) are the available three methods. The Z-score indicates how many standard deviations any value is from the mean. ${ }^{25}$

In contrast with a previous research done on 2002, also based on local data, presented the anthropometric parameters using the percentile method ${ }^{18,}$ our study is the first tool in Egypt to use LMS and $Z$ score growth parameters method that provide more accuracy than percentiles that were used before. When compared with this study in Egypt, the previous study was done only on one governorate of Egypt and was based on percentile, but our report was done in many governorates that were representative to Egypt and based on LMS and Z score method that is more accurate.

Variation in the environmental conditions and the ethnicity factor developed the necessity for the development of tailored charts from representative samples, ${ }^{26} 27$ that was and still conducted by many developed, ${ }^{28-30}$ and developing countries. ${ }^{31-33}$ In Egypt, this is the first national Z score growth charts for school children and adolescents that was developed in spite of using other charts.

Weight for age was not calculated beyond 10 years of age as during the pubertal growth spurt, the height increases rapidly more than weight making it not an accurate measure of nutritional status beyond 10 years. $^{19}$

After comparison of weight, height and BMI for age values of both sexes of the children and adolescents who participated in the present study with the WHO values, ${ }^{19}$ there was no statistically significant difference between the Egyptian $\mathrm{Z}$ score charts and the reference values of WHO. The P values of weight for age in boys and girls were 0.142 and $0.229(P>0.05)$ respectively. The $P$ values of height for age in boys and girls were 0.469 and $0.361(P>0.05)$ respectively. The $P$ values of $B M l$ for age in boys and girls were 0.492 and $0.316(P>0.05)$ respectively. This mean that WHO growth charts may be appropriate for monitoring growth and nutritional status on Egyptian children as the growth pattern in our large population were closer to growth charts of WHO.

WHO Multicenter Growth Reference Study was conducted to provide a single international standard representative for the physiological growth for all children everywhere, regardless of ethnicity, socioeconomic status and type of feeding, and our study supports this hypothesis.

\section{Conclusion}

The L, M, and S parameters and Z-scores for Egyptian school children and adolescents presented in this report provide nationally representative reference that will facilitate more accurate assessment of growth 
and nutritional status of Egyptian children and comparison with other populations under different clinical conditions. In absence of these local charts, we recommend using WHO growth charts.

\section{Declarations}

Acknowledgements:

No words could express our deep feelings towards our patients and teamwork.

\section{Author Contributions Statement:}

Idea and design: AE-S, ZO, AE-B, WB.

Participant enrolment and data collection: AE-S, ZO, AE-B, MA, AM, AK, HR, GB, AS, WG, WB.

Data interpretation: AE-S, ZO, AE-B, WB. Manuscript writing: AE-B, ZO.

Statistical analysis: ZK.

Manuscript revision: AE-S, ZO, FE, DA,.MS,AE-B, WB, ZK.

Conflict of Interest: The authors declare that the research was conducted in the absence of any commercial or financial relationships that could be construed as a potential conflict of interest.

Funding: This research received no specific grant from any funding agency in the public, commercial or not-for-profit sectors.

Provenance and peer review: Not commissioned; externally peer reviewed.

Data sharing statement: No additional data are available.

\section{References}

1. Black RE, Allen LH, Bhutta ZA, Caulfield LE, de Onis M, Ezzati M, et al: Maternal and child undernutrition: global and regional exposures and health consequences. $2008 \mathrm{Jan}$ 19;371(9608):243-60. DOI: 10.1016/S0140-6736(07)61690-0.

2. Bonthuis M, van Stralen KJ, Verrina E, Edefonti A, Molchanova EA, Hokken-Koelega AC, et al: Use of national and international growth charts for studying height in European children: development of up-to-date European height-for-age charts. PLoS One. 2012;7(8):e42506. DOI:

10.1371/journal.pone.0042506.

3. deOnis M, Wijnhoven TM, Onyango AW: Worldwide practices in child growth monitoring. $J$ Pediatr. 2004 Apr;144(4):461-5. DOl: 10.1016/j.jpeds.2003.12.034. 
4. Foster BJ, Leonard MB: Measuring nutritional status in children with chronic kidney disease. Am J ClinNutr. 2004 Oct;80(4):801-14. DOI: 10.1093/ajcn/80.4.801.

5. Physical status: the use and interpretation of anthropometry. Report of a WHO Expert Committee. World Health Organ Tech Rep Ser. 1995;854:1-452.

6. Ayatollahi SM, Sharafi Z, Haem E: Child Weight Growth Chart and Its Associated Factors in Birth Cohort of Maku Using a Growth Curve Model and LMS Method. Glob J Health Sci. 2015 Apr 19;7(6):181-6. DOl: 10.5539/gjhs.v7n6p181.

7. Abalkhail B, Shawky S: Comparison between body mass index, triceps skin fold thickness and midarm muscle circumference in Saudi adolescents. Ann Saudi Med. 2002 Sep-Nov;22(5-6):324-8. DOl: 10.5144/0256-4947.2002.324.

8. Wang C, Hou XH, Zhang ML, Bao YQ, Zou YH, Zhong WH, et al: Comparison of body mass index with body fat percentage in the evaluation of obesity in Chinese. Biomed Environ Sci. 2010 Jun;23(3):1739. DOI: 10.1016/S0895-3988(10)60049-9.

9. Nooyens AC, Koppes LL, Visscher TL, Twisk JW, Kemper HC, Schuit AJ, et al: Adolescent skinfold thickness is a better predictor of high body fatness in adults than is body mass index: the Amsterdam Growth and Health Longitudinal Study. Am J ClinNutr. 2007 Jun;85(6):1533-9DOI: 10.1093/ajcn/85.6.1533.

10. Welborn TA, Knuiman MW, Vu HT: Body mass index and alternative indices of obesity in relation to height, triceps skinfold and subsequent mortality: the Busselton health study. Int J Obes Relat Metab Disord. 2000 Jan;24(1):108-15. DOl: 10.1038/sj.ijo.0801093.

11. de Almeida CA, Pinho AP, Ricco RG, Elias CP: Abdominal circumference as an indicator of clinical and laboratory parameters associated with obesity in children and adolescents: comparison between two reference tables. J Pediatr (Rio J). 2007 Mar-Apr;83(2):181-5. DOI: 10.2223/JPED. 1604.

12. Himes $\mathrm{JH}$ : Challenges of accurately measuring and using BMI and other indicators of obesity in children. 2009 Sep;124 Suppl 1:S3-22. DOI: 10.1542/peds.2008-3586D.

13. Krebs NF, Himes JH, Jacobson D, Nicklas TA, Guilday P, Styne D: Assessment of child and adolescent overweight and obesity. 2007 Dec;120 Supp/ 4:S193-228. DOI: 10.1542/peds.2007-2329D.

14. Walker CL, Rudan I, Liu L, Nair H, Theodoratou E, Bhutta ZA, O'Brien KL, Campbell H, Black RE: Global burden of childhood pneumonia and diarrhoea. The Lancet. 2013 Apr 20;381(9875):1405-16.

15. Xu S, Xue Y: Pediatric obesity: Causes, symptoms, prevention and treatment. Experimental and therapeutic medicine. 2016 Jan 1;11(1):15-20.

16. ABASSY A, HUSSEIN M, AREF M, HAMAD S, MORSY M, KASSEM A, et al: Growth and development of the Egyptian child. First ed. 1972.

17. El-Nofely A, Kamel N, Abou-Zeid AW et al: Attained Weight, Stature and Weight/Stature Index for Egyptian Children Aged 6-18 Years. Cairo Area, 1980-1982. J. Anthropol. 4, 275-286 (1989).

18. Ghali I, Salah N, Hussien F, Erfan M, El-Ruby M, Mazen I, Sabry M, Abd El-Razik M, Saad M, Hossney S, Ismaail and Abd El-Dayem: Egyptian growth curves for infants, children and adolescents. 
Published in: Crecere nel mondo. Satorio A, Buckler JMH and Marazzi N (2008), Ferring Publisher, Italy.

19. DeOnis M, Onyango AW, Borghi E, Siyam A, Nishida C, Siekmann J: Development of a WHO growth reference for school-aged children and adolescents. Bull World Health Organ. 2007 Sep;85(9):6607.DOl: 10.2471/blt.07.043497.

20. Kuczmarski RJ, Ogden CL, Guo SS, Grummer-Strawn LM, Flegal KM, Mei Z, et al: 2000 CDC Growth Charts for the United States: methods and development. Vital Health Stat 11. 2002 May;(246):1-190.

21. El-Zanaty F, Way A: Egypt health issue survey 2015. Cairo: Egyptian Ministry of Health and Population. 2015. https://dhsprogram.com/pubs/pdf/FR313/FR313.pdf

22. Cole TJ, Green PJ: Smoothing reference centile curves: the LMS method and penalized likelihood. Stat Med. 1992 Jul;11(10):1305-19. DOI: 10.1002/sim.4780111005.

23. Cole TJ, Freeman JV, Preece MA: British 1990 growth reference centiles for weight, height, body mass index and head circumference fitted by maximum penalized likelihood. Stat Med. $1998 \mathrm{Feb}$ 28;17(4):407-29.

24. Pan H, Cole TJ: A comparison of goodness of fit tests for age-related reference ranges. Stat Med. 2004 Jun 15;23(11):1749-65. DOl: 10.1002/sim. 1692.

25. El Mouzan MI, Al Salloum AA, Alqurashi MM, AlHerbish AS, Al Omar A: The LMS and Z scale growth reference for Saudi school-age children and adolescents. Saudi J Gastroenterol. 2016;22(4):331-6. DOI: 10.4103/1319-3767.187608.

26. Freedman DS, Khan LK, Serdula MK, Ogden CL, Dietz WH: Racial and ethnic differences in secular trends for childhood BMl, weight, and height. 2006;14:301-8. DOI: 10.1038/oby.2006.39.

27. Deaton A: Height, health, and development. Proc Natl Acad Sci. 2007;104:13232-13237. DOl: 10.1073/pnas.0611500104.

28. Wright CM, Booth IW, Buckler JM, Cameron N, Cole TJ, Healy MJ, et al: Growth reference charts for use in the United Kingdom. Arch Dis Child. 2002;86:11-14. DOl: 10.1136/adc.86.1.11.

29. Tinggaard J, Aksglaede L, Sørensen K, Mouritsen A, Wohlfahrt-Veje C, Hagen CP, et al: The 2014 Danish references from birth to 20 years for height, weight and body mass index. Acta Pædiatrica. 2014;103:214-224. DOI: 10.1111/apa.12468.

30. Scherdel P, Botton J, Rolland-Cachera MF, Léger J, Pelé F, Ancel PY, et al: Should the WHO Growth Charts Be Used in France? PLoS One. 2015;10(3):e0120806. DOI: 10.1371/journal.pone.0120806.

31. Bong Y, Shariff AA, Mohamed AM, Merican AF: Malaysian growth centiles for children under six years old. Ann Hum Biol. 2015;42:108-115. DOI: 10.3109/03014460.2014.912679.

32. Payande A, Tabesh H, Shakeri MT, Saki A, Safarian M: Growth Curves of Preschool Children in the Northeast of Iran: A Population-Based Study Using Quantile Regression Approach.Glob J Health Sci. 2013;5(3):9-15. Published 2013 Jan 14. doi:10.5539/gjhs.v5n3p9.

33. Zong XN, Li H: Construction of a New Growth References for China Based on Urban Chinese Children: Comparison with the WHO Growth Standards.PLOS ONE. 2013;8(3):e59569. DOI: 
10.1371/journal.pone.0059569.

\section{Table 1}

Table (1): Number of participating children in each age group/year 


\begin{tabular}{|c|c|c|}
\hline & Boy & Girl \\
\hline $\mathbf{5}$ years & 1199 & 1135 \\
\hline $\mathbf{6}$ years & 1259 & 1096 \\
\hline $\mathbf{7}$ years & 1288 & 1082 \\
\hline $\mathbf{8}$ years & 1290 & 1050 \\
\hline $\mathbf{9}$ years & 1244 & 1026 \\
\hline $\mathbf{1 0}$ years & 1283 & 1088 \\
\hline $\mathbf{1 1}$ years & 1305 & 1030 \\
\hline $\mathbf{1 2}$ years & 1254 & 1047 \\
\hline $\mathbf{1 3}$ years & 1284 & 1063 \\
\hline $\mathbf{1 4}$ years & 1247 & 1053 \\
\hline $\mathbf{1 5}$ years & 1299 & 1036 \\
\hline $\mathbf{1 6}$ years & 1261 & 1049 \\
\hline $\mathbf{1 7}$ years & 1248 & 1073 \\
\hline $\mathbf{1 8}$ years & 1210 & 1034 \\
\hline $\mathbf{1 9}$ years & 1243 & 1046 \\
\hline Total & 18914 & 15908 \\
\hline & & \\
\hline
\end{tabular}

Figures 


\section{Weight for age Boys 5 years to 10 years (Egyptian Z score)}

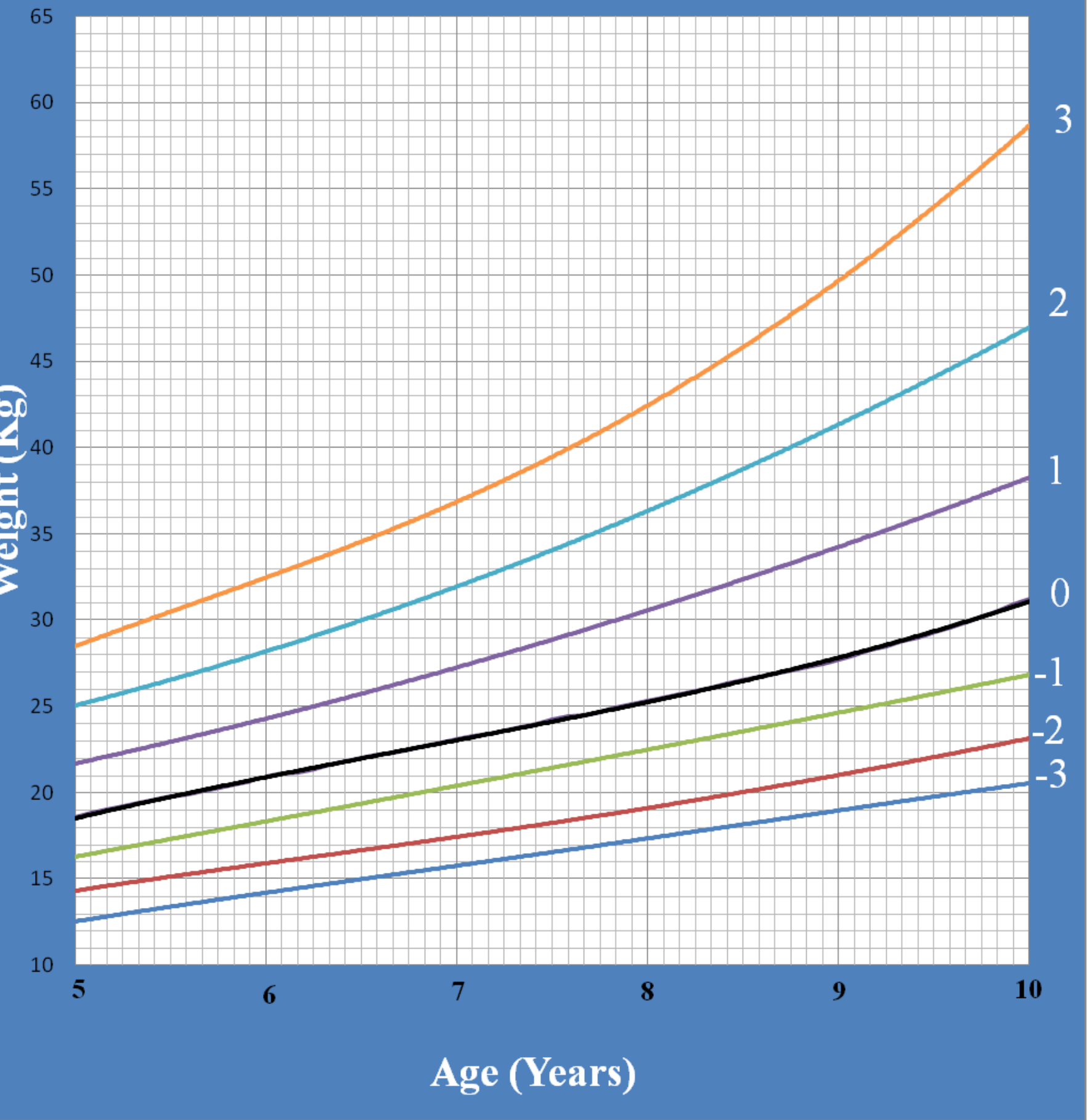

\section{Figure 1}

shows the Egyptian Z score weight for age from 5 years to 10 years for boys 


\section{Weight for age Girls 5 years to 10 years}

(Egyptian Z score)

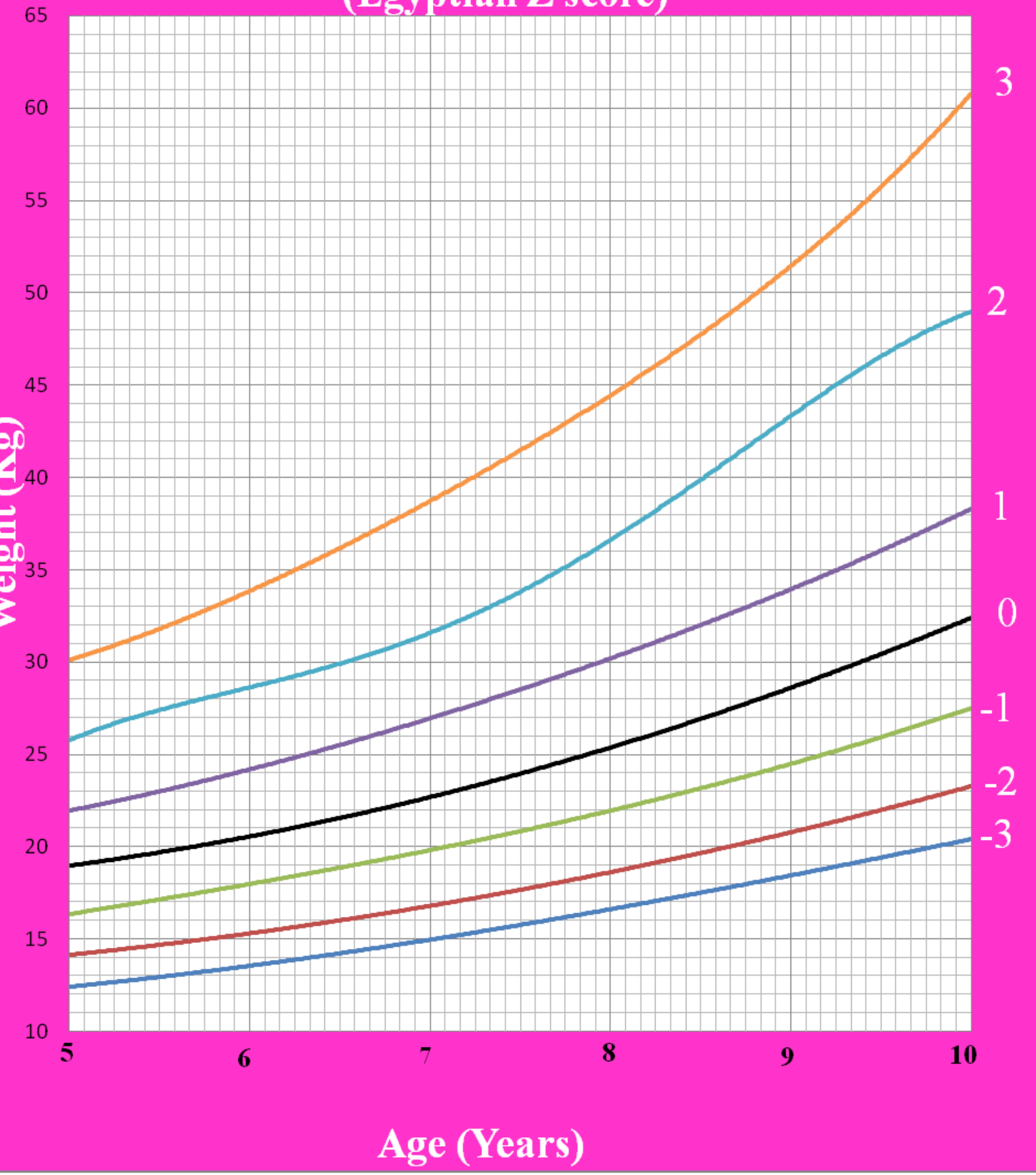

\section{Figure 2}

shows the Egyptian Z score weight for age from 5 years to 10 years for girls 


\section{Height for age Boys 5 year to 19 year (Egyptian Z score)}

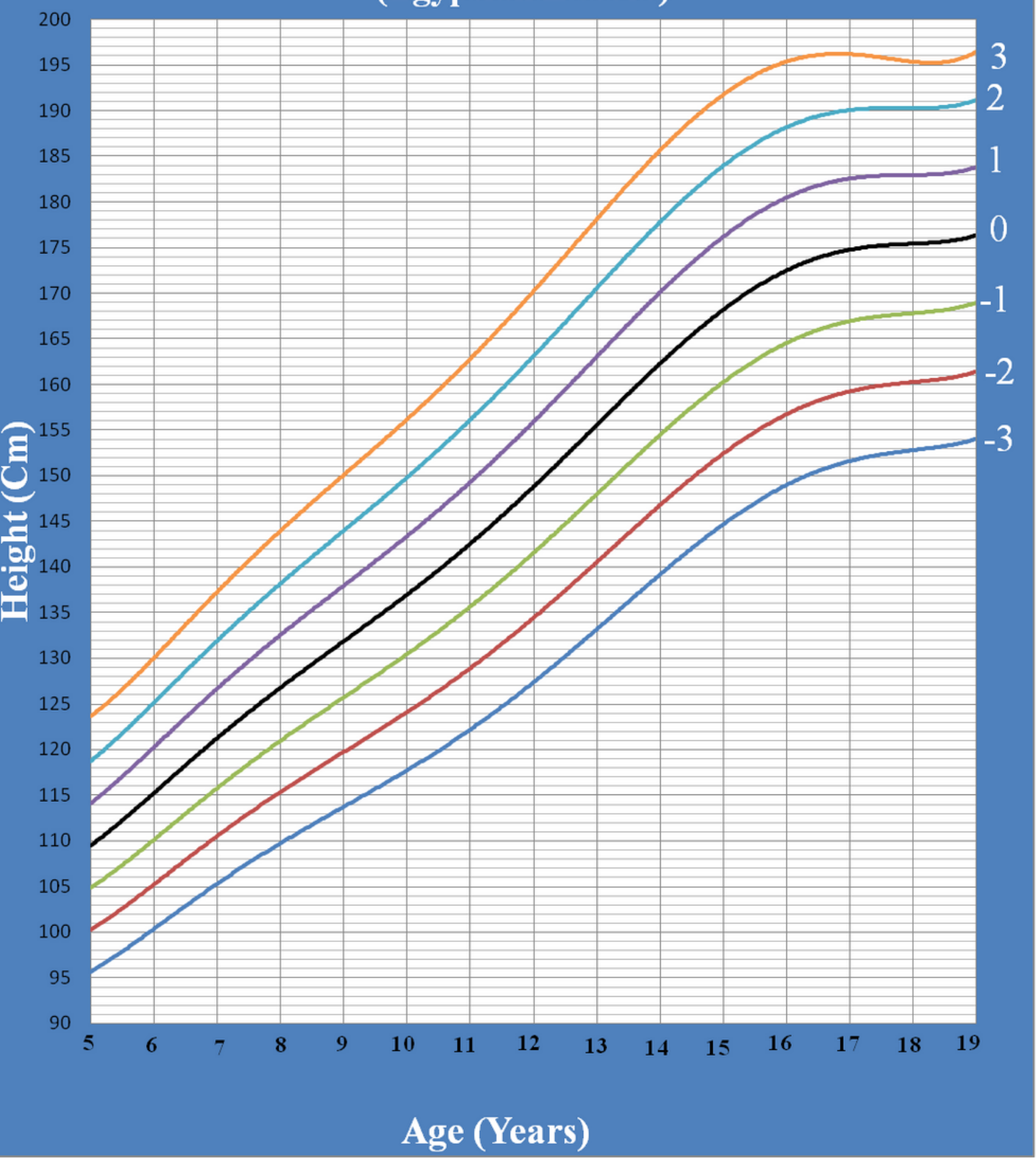

\section{Figure 3}

shows the Egyptian Z score height for age from 5 years to 19 years for boys 


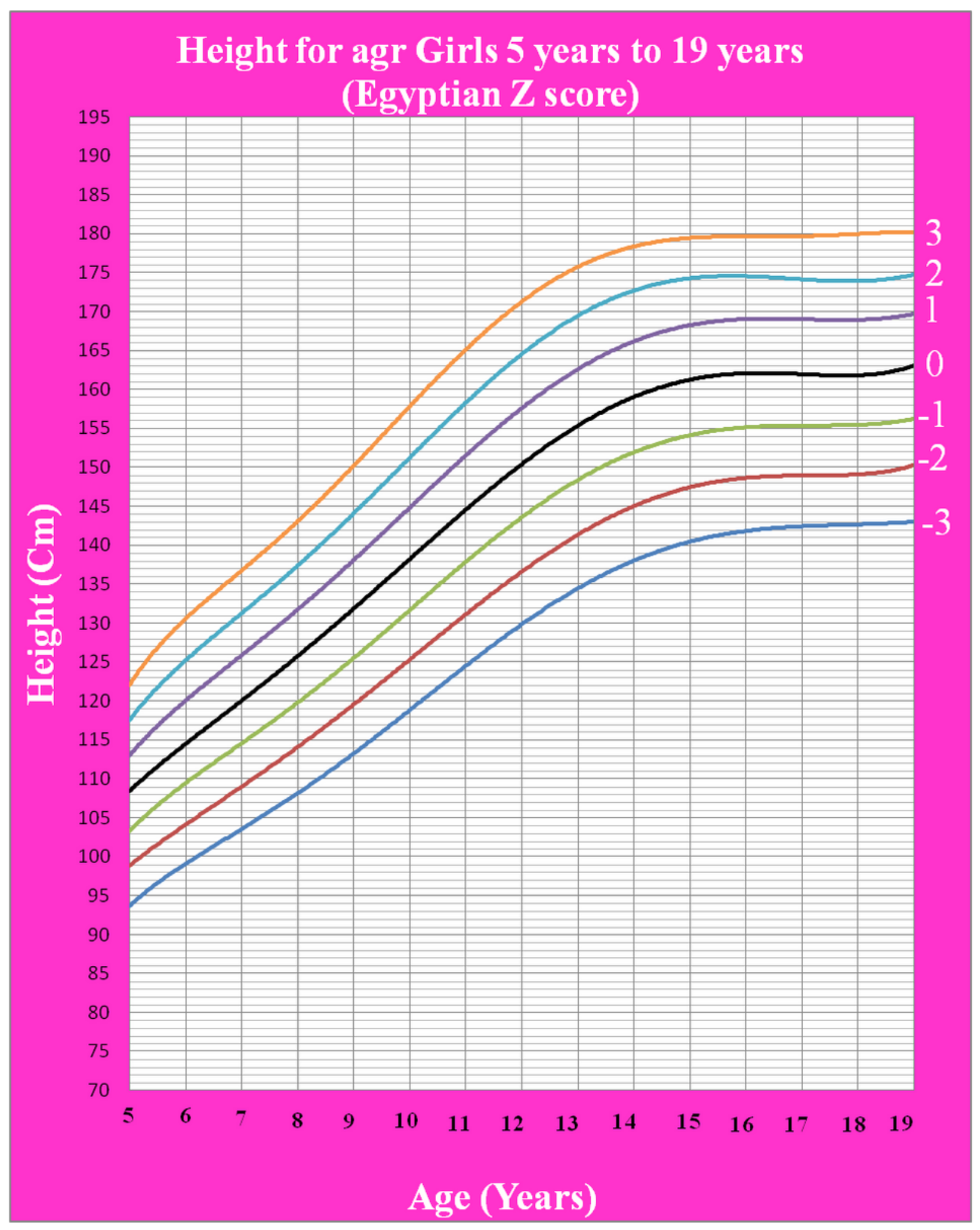

Figure 4

shows the Egyptian Z score height for age from 5 years to 19 years for girls 


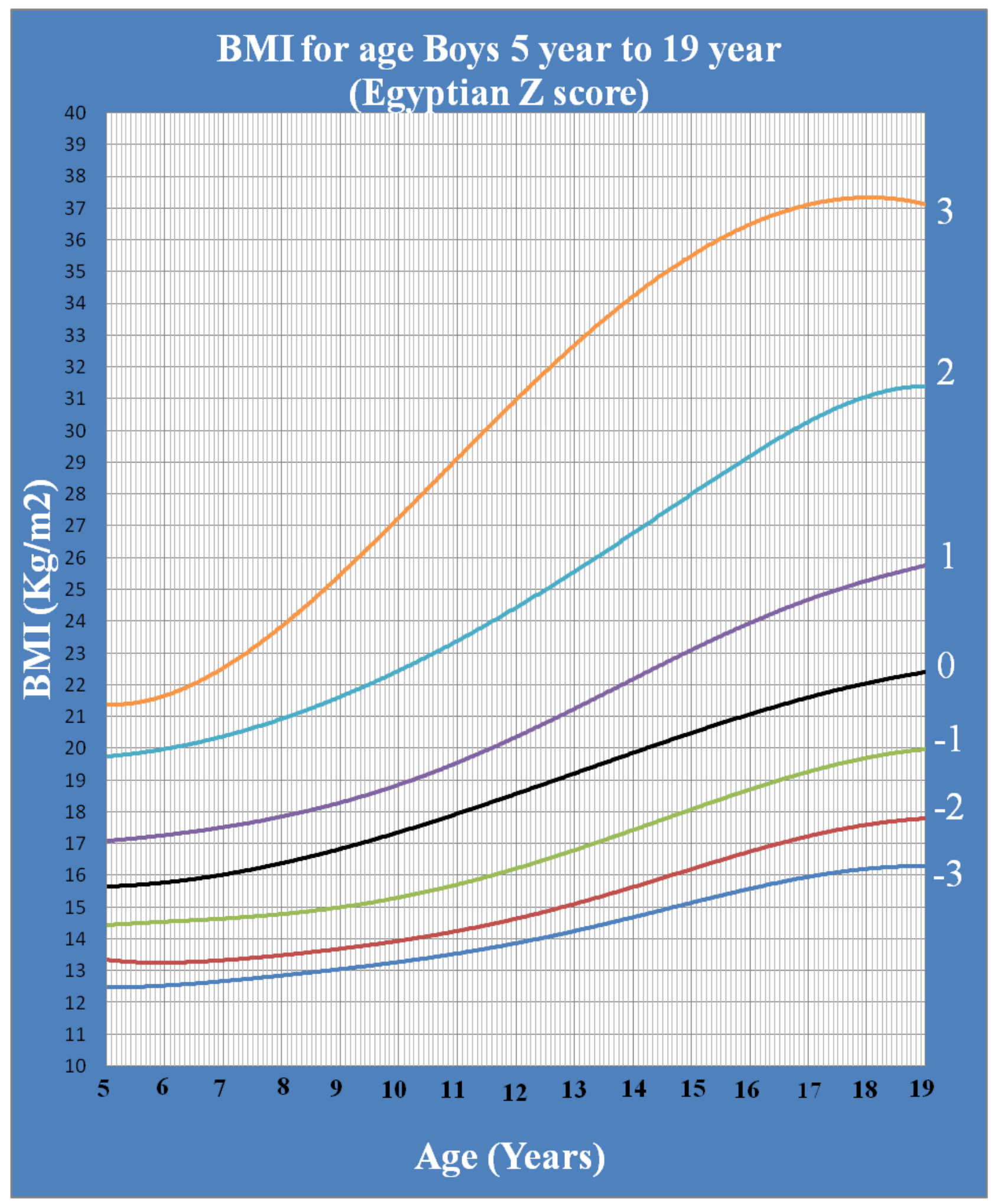

Figure 5

shows the Egyptian Z score BMI for age from 5 year to 19 years for boys 


\section{BMI for age Girls 5 years to 19 years (Egyptian Z score)}

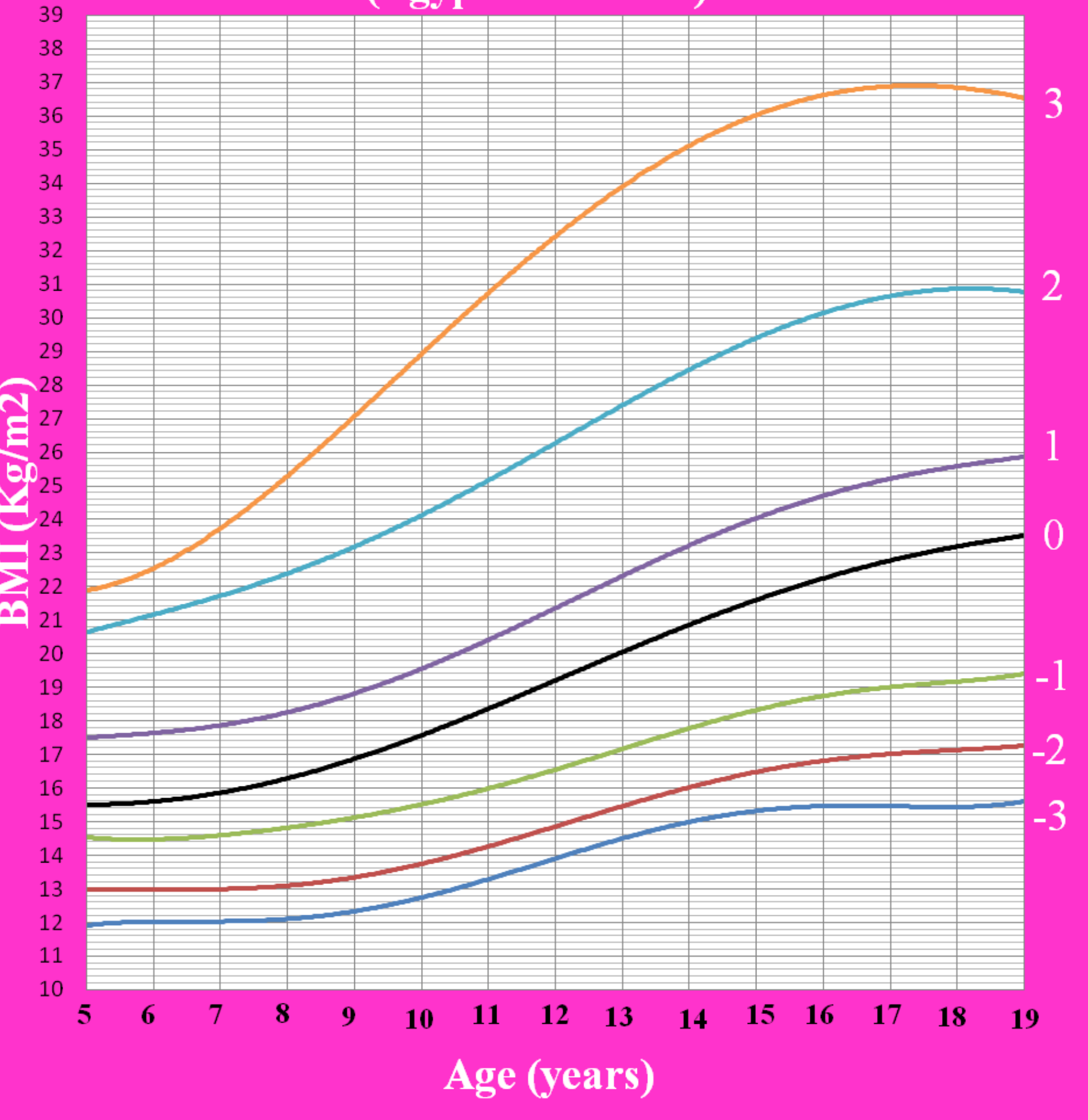

Figure 6

shows the Egyptian Z score BMI for age from 5 years to 19 years for girls 


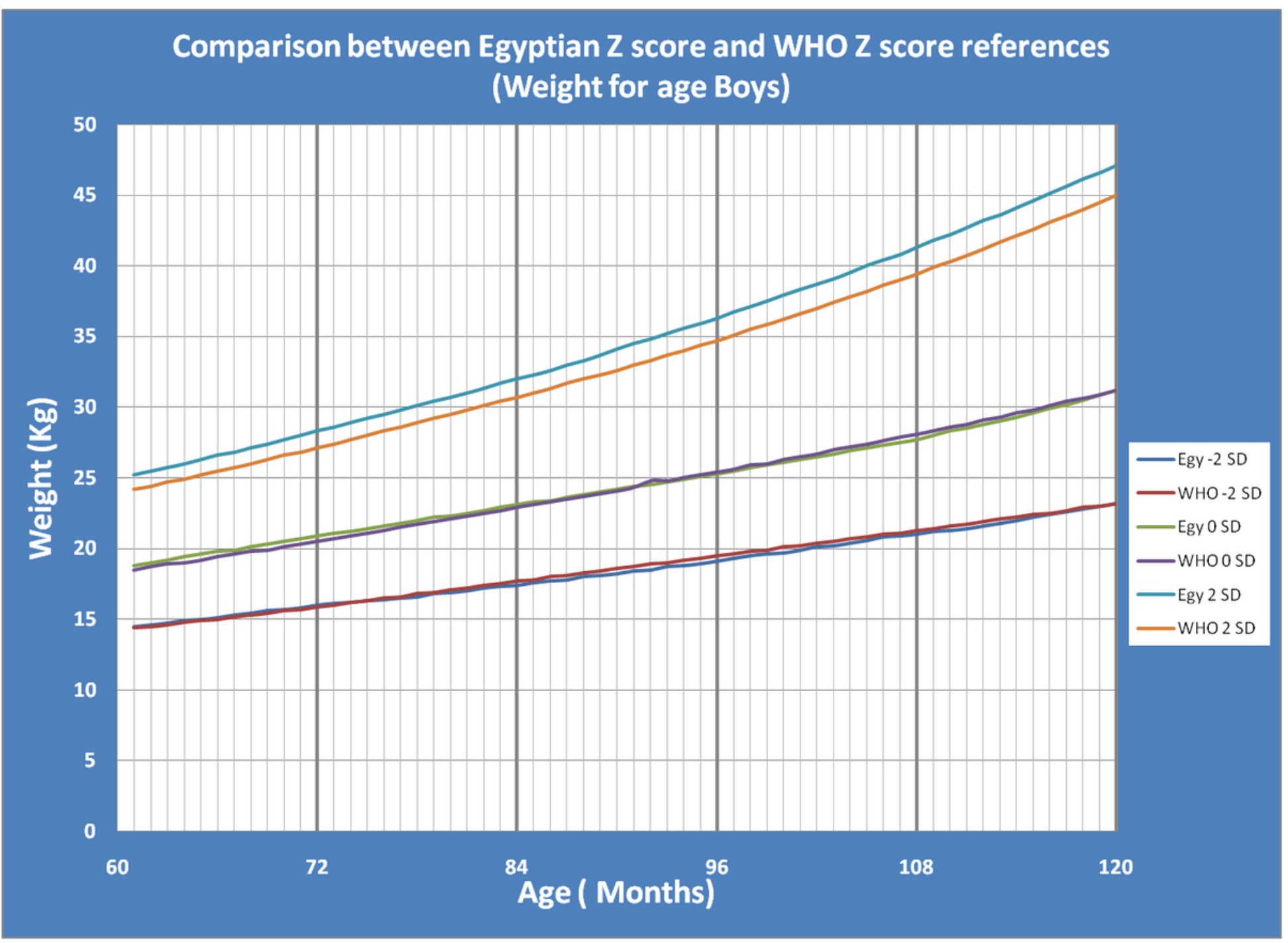

Figure 7

shows the comparison between Egyptian Z score and WHO Z score references value (weight for age in boys) 


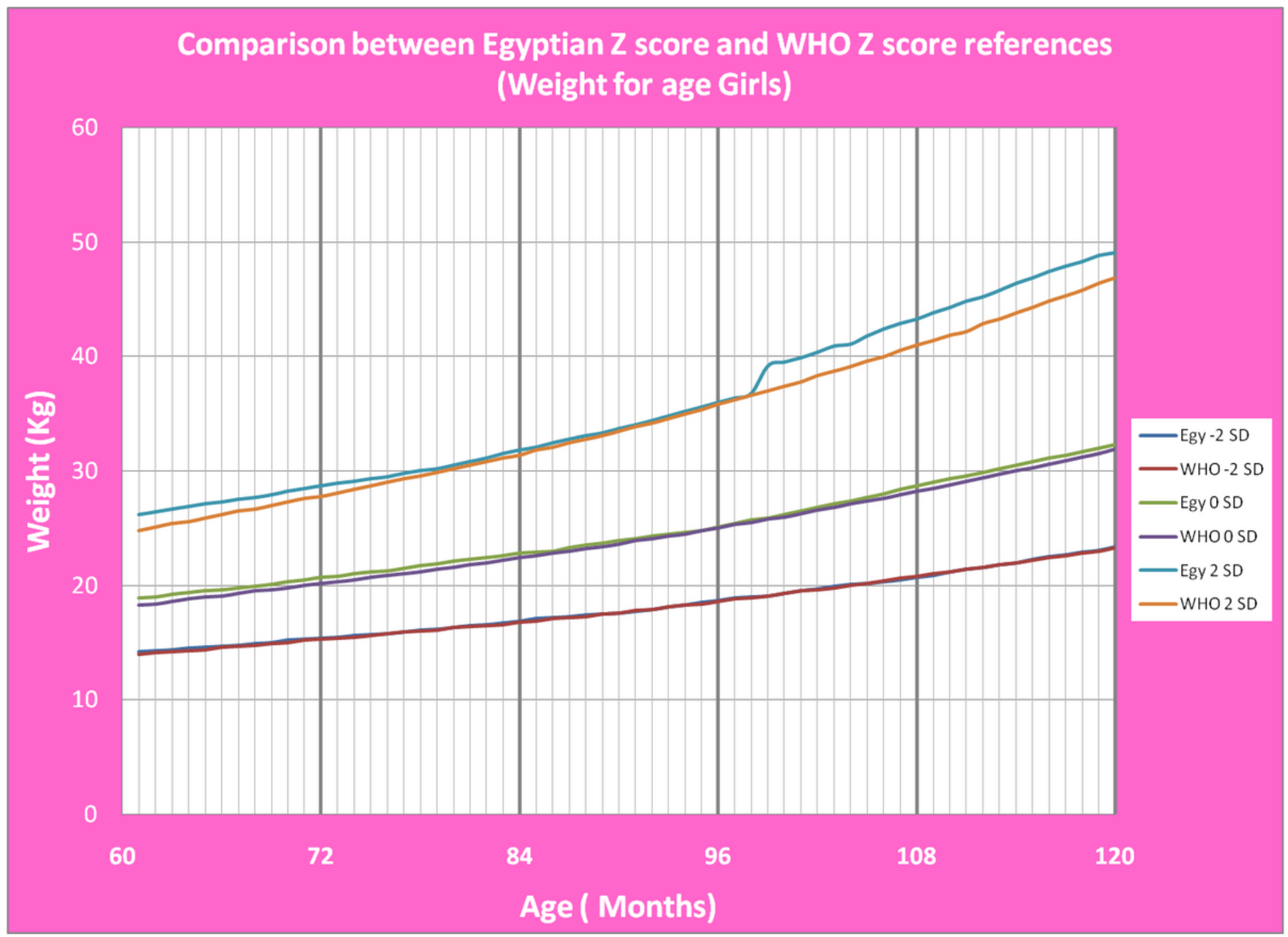

Figure 8

shows the comparison between Egyptian Z score and WHO Z score references value (weight for age in girls) 


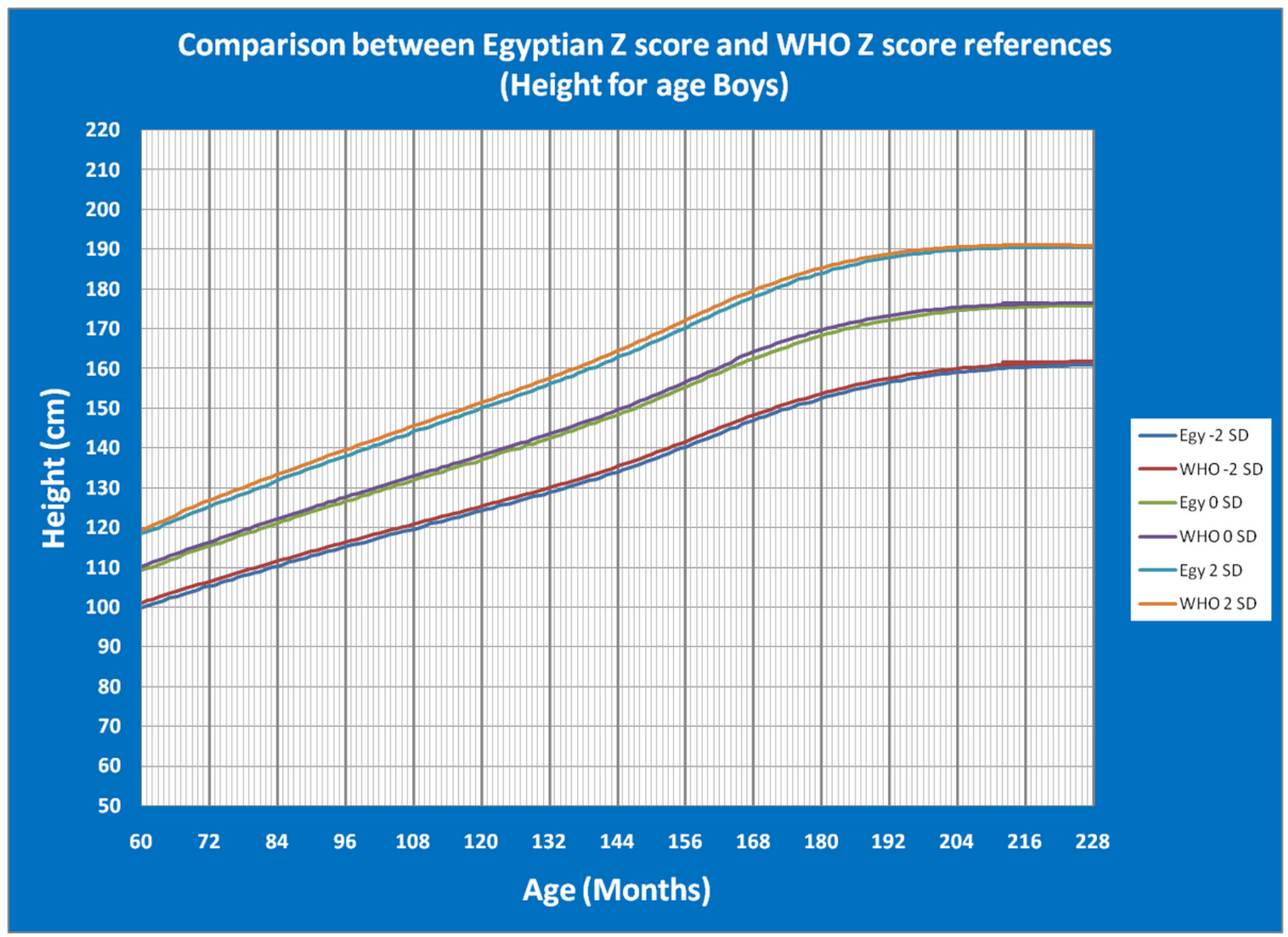

Figure 9

shows the comparison between Egyptian Z score and WHO Z score references value (Height for age in boys) 


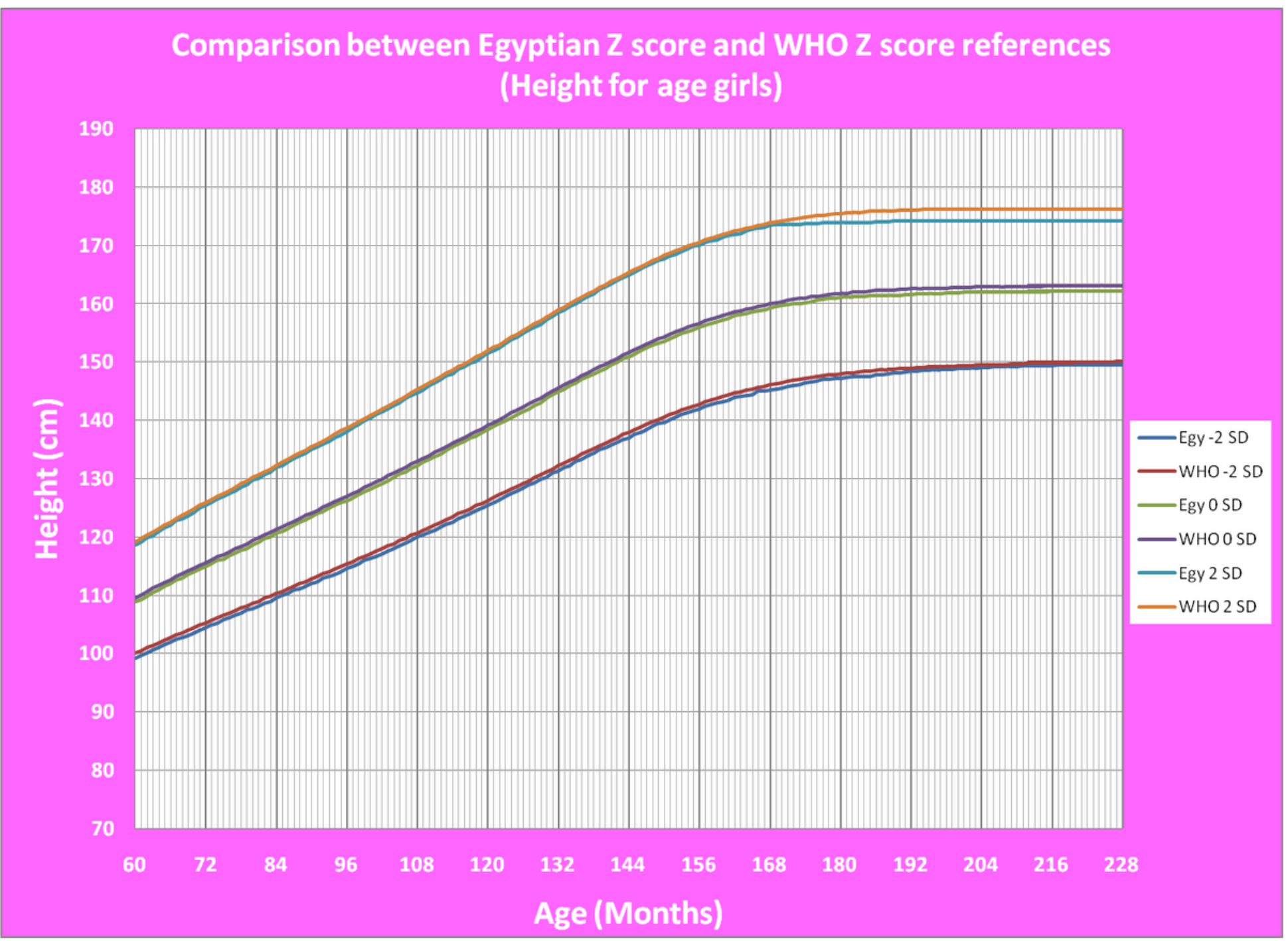

Figure 10

shows the comparison between Egyptian Z score and WHO Z score references value (Height for age in girls)

\section{Supplementary Files}

This is a list of supplementary files associated with this preprint. Click to download.

- supplementaryfile.docx 